\title{
Study on Wire Rope Brace Design Method of Prestressed Braced Steel Moment Frame
}

\author{
Ailin Zhang ${ }^{1,2}$, Liang Zhao,"* and Xuechun Liu ${ }^{1,2}$ \\ ${ }^{1}$ College of Architecture and Civil Engineering, Beijing University of Technology, Beijing 100124, China \\ ${ }^{2}$ Beijing Engineering Research Center of High-Rise and Large-Span Prestressed Steel Structure, Beijing University of \\ Technology, Beijing 100124, China
}

\begin{abstract}
To study the design method of sectional area and initial tension of wire rope brace of the prestressed braced steel moment frame structure system, theoretical analysis of this structure system is conducted in this paper. The lateral stiffness formula is derived. It reveals the lateral stiffness is related to the lateral stiffness of bare steel moment frame, story height, the distance between column and lower end of brace, story drift, material properties and sectional properties of wire rope. The lateral stiffness increases with the growth of story drift and the relationship curve is a concave shape. It is presented the initial prestress degree design formula and method in light of the criterion for determining initial prestress degree. The story drift decreases with the growth of wire rope sectional area and the relationship curve is a concave shape, in terms of this, a wire rope sectional area design formula and method are proposed. The validation of the proposed design formula and method of wipe rope brace is proved by an example analyzed using finite element software package ABAQUS.
\end{abstract}

Keywords: Design method, initial tension, sectional area, prestressed braced steel moment frame, wire rope brace.

\section{INTRODUCTION}

Moment-resisting steel frames in regions of high seismicity are commonly designed to have high lateral stiffness to restraint the lateral story displacement within a specified range [1]. However, unexpected events, such as extremely severe earthquakes, might cause unacceptably large story drift. Important tasks in structure design are the characterization of maximum story drift and damage distribution induced into building frames under a given external load. The maximum story drift has been regarded as the primary index for assessing the overall damage to a building.

Previous researches have underscored the necessity of lateral stiffness retrofitting of existing steel moment frames. There are several types of retrofitting methods have been investigated, such as thin infill panels [2] and bracing system. The bracing system can increase the story lateral stiffness and strength effectively. For improving the seismic resistance in the bracing members, an eccentrically braced frame [3, 4], a dissipative bracing system [5], a displacement-restraint bracing [6] and a non-compression brace [7] have been improved. An ordinary braced frame has complicated restoring force characteristics under seismic loading due to compressive brace buckling [8]. Buckling-

*Address correspondence to the author at the College of Architecture and Civil Engineering, Beijing University of Technology, Beijing 100124, China; Tel: +8613426488880; Fax: +86-010-67391815;

E-mail: david.1224@126.com restrained brace [9] has been investigated to prevent buckling occurrence in the bracing members, but it has complex details and heavy-weight. The brace system with semi-active and active control has been proposed and investigated to maintain the structure system in a nonresonant state $[10,11]$. Some researchers have examined the application of these braces $[12,13]$.

The prestressed braced steel moment frame (PBSMF) presents a retrofit method using wire rope (cable) bracing for steel moment frame. It is an innovation using flexible wire rope (cable) instead of rigid brace. All the wire ropes in PBSMF have initial tensile force. Previous study on PBSMF demonstrates that it can increase the lateral stiffness and guarantee story drift in a specified range, as well as reduce the residual deformation [6]. By optimizing the initial tensile force of wire ropes, PBSMF can prevent buckling from occurring in the bracing members. Compared with other bracing systems, it is characterized by smaller weight and sectional area, which makes it easier to move and install. It is an essential problem how to determine the sectional area and initial tensile force of the wire ropes in PBSMF.

Theoretical analysis is conducted to investigate the performance of PBSMF in this paper. It is derived that the design formulas of sectional area and initial tensile force of wire rope brace in light of theoretical analysis results. Based on the specified story drift, a design method of sectional area and initial tensile force is proposed. The design method can optimize wire ropes with a smaller sectional area and more reasonable initial tension. An example of four-story three- 
span PBSMF is conducted to validate the feasibility of the design method.

\section{LATERAL STIFFNESS OF PBSMF}

PBSMF consists of two parts, one is bare steel moment frame, and the other is wire rope (cable) brace. So the lateral stiffness of PBSMF can be written as follow:

$$
D=D_{f}+D_{C}
$$

where, $D$ represents the lateral stiffness of PBSMF, $D_{f}$ and $D_{c}$ represent the lateral stiffness of bare steel moment frame and wire rope brace respectively.

In order to analyze PBSMF easily and accurately, the following simplifications are assumed:

1. Ignore the deformation of beams

2. Story height remains a constant in the PBSMF subjected to external loads.

\section{All members are in elastic stage.}

Wire rope brace presents two kinds of stress state, which are stress-increased state and stress-decreased state respectively, when the PBSMF is subjected to horizontal external loads. All the wire rope braces are in an initial stress state. Compared with the initial stress, stress-increased wire rope brace (SIWRB) refers to the wire rope which stress is bigger than it, in contrast, stress-decreased wire rope brace (SDWRB) refers to the wire rope which stress is smaller than it.

In order to study the lateral stiffness of the PBSMF, it is necessary to calculate the horizontal external load which can make the structure generate a unit story drift. It can be expressed by the following equation:

$$
\delta P=D_{f} \delta+D_{C} \delta
$$

where, $\delta$ denotes the unit story drift, $\delta P$ denote the external load that can generate unit story drift in the PBSMF.

The deformation of PBSMF under $P+\delta P$ is shown in Fig. (1), where, $H$ is the story height, $B$ is the distance between column and lower end of brace, $x$ is the story drift,
$P$ is the horizontal external load with respect to story drift $x$, $L_{l}^{x}$ and $L_{2}^{x}$ denote the length of SDWRB and SIWRB under $P$ respectively, $\alpha_{l}^{x}$ represents the angle between SDWRB and the horizontal plane under $P, \alpha_{2}^{x}$ represents the angle between SIWRB and the horizontal plane under $P, L_{1}^{x+\hat{\delta}}$ and $L_{2}^{x+\delta}$ represent the length of SDWRB and SIWRB under $P+\delta P$ respectively, $\alpha_{1}^{x+\delta}$ is the angle between SDWRB and the horizontal plane under $P+\delta P, \alpha_{2}^{x+\delta}$ is the angle between SIWRB and the horizontal plane under $P+\delta P$.

According to the geometrical relationship of deformed model and undeformed model, the compressed length of SDWRB, $\Delta L_{1}^{\delta}$, and the tensile length of SIWRB, $\Delta L_{2}^{\delta}$, can be expressed by the following equation:

$$
\begin{aligned}
& \Delta L_{1}^{\delta}=L_{1}^{x}-L_{1}^{x+\delta} \\
& \Delta L_{2}^{\delta}=L_{2}^{x+\delta}-L_{2}^{x}
\end{aligned}
$$

In terms of the force equilibrium equation of the deformed structure, when the structure generate a unit story drift, the horizontal external load can be written as:

$$
\delta P=D_{f} \delta+\Delta T_{1} \cos \alpha_{1}^{x+\delta}+\Delta T_{2} \cos \alpha_{2}^{x+\delta}
$$

where, $\Delta T_{1}$ is the decreased tension of SDWRB, $\Delta T_{2}$ is the increased tension of SIWRB.

Based on the tension of SDWRB and SIWRB, the geometrical relationship of deformed model and Hooke law, the lateral stiffness of PBSMF can be calculated using the following equation:

$$
\begin{aligned}
D= & D_{f}+\left(1-\frac{\sqrt{H^{2}+(B-x-1)^{2}}}{\sqrt{H^{2}+(B-x)^{2}}}\right) E_{C} A_{C} \cos \left(\arctan \frac{H}{B-x-1}\right) \\
& +\left(\frac{\sqrt{H^{2}+(B+x+1)^{2}}}{\sqrt{H^{2}+(B+x)^{2}}}-1\right) E_{C} A_{C} \cos \left(\arctan \frac{H}{B+x+1}\right)
\end{aligned}
$$

where, $E_{C}$ represents the elastic modulus of wire rope, $A_{C}$ represent the sectional area of wire rope.

Eq. (6) indicates that the lateral stiffness of the PBSMF is related to the lateral stiffness of bare steel moment frame, story height, the distance between column and lower end of

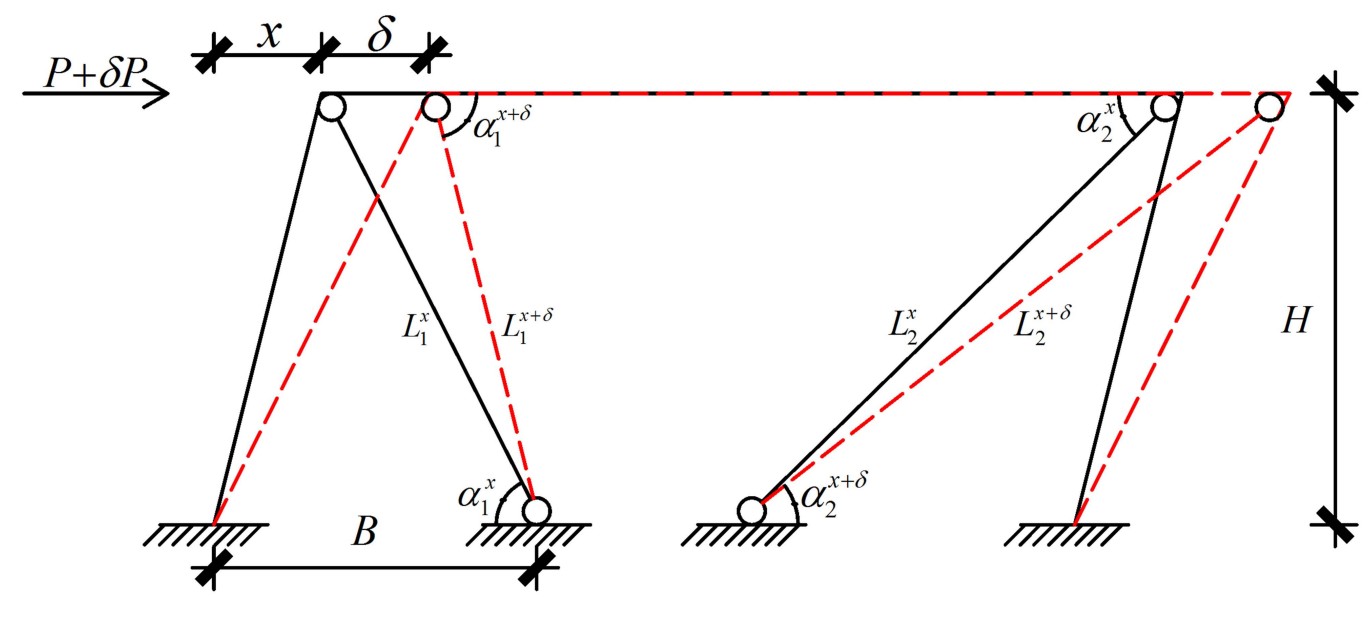

Fig. (1). Deformation comparison of PBSMF under $P+\delta P$. 


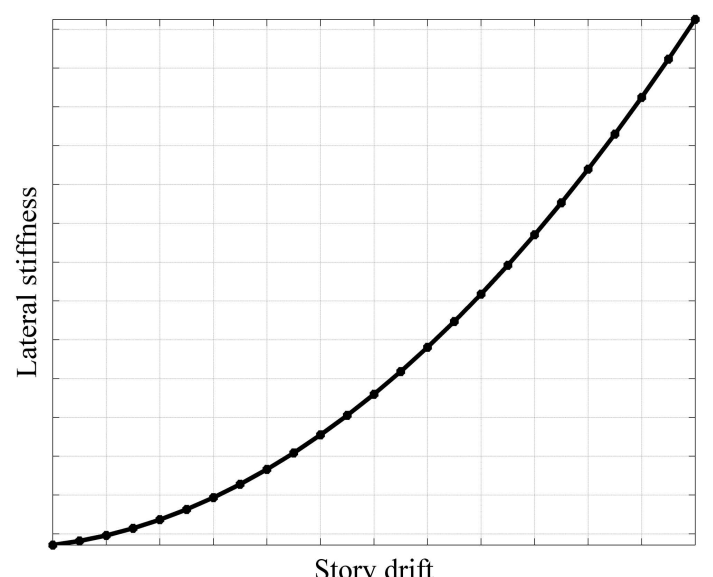

Fig. (2). Relation curve of story drift and lateral stiffness.

brace, story drift, material properties and sectional properties of wire rope. Fig. (2) depicts the relationship between story drift and lateral stiffness of the PBSMF, while other parameters are constant. Fig. (2) shows that the lateral stiffness increases with the growth of story drift, and the curve is a concave shape.

\section{INITIAL PRESTRESS DEGREE FORMULA}

\subsection{Criterion for Determining Initial Tensile Force}

The PBSMF subjected to horizontal load has three types of force mode. The first force mode is all the components are participate in the work to resist external loads, include steel moment frame, SDWRB and SIWRB. The second force mode is the SDWRB, whose tensile stress is less than zero, quit working due to the increase of story drift, there are only steel frame and SIWRB acting at the moment. The third force mode is the SIWRB, whose tensile stress exceeds the ultimate tensile stress, is broken due to the story drift reaching a very large value, meanwhile PBSMF has the same performance as bare steel moment frame.

In terms of the three types of force mode, we can obtain the initial tensile force criterion of wire ropes, which is the tensile stress of SDWRB is more than zero and the tensile stress of SIWRB is less than the designed acceptable stress under designed external loads. It can be expressed as follow:

$$
T_{d}>T_{i}\left(F_{d}, \gamma\right)>0(i=1,2,3 \ldots n)
$$

where, $T_{d}$ represents the designed ultimate tension, $F_{d}$ represents the designed external force, $\gamma$ is the initial pretress degree of wire rope, $T_{i}$ is the tensile force of wire rope $i, i$ denotes the number of wire rope, $n$ is the total number of wire ropes.

The definition of prestress degree is the ratio of the tensile stress to the ultimate stress of wire rope. The definition of safe capacity is the ratio of the tension, which the wire rope can continue to bear, to the ultimate tension of the wire rope. Thus, the more the initial prestress degree sets, the less the safe capacity obtains. The values of prestress degree and safe capacity are in the range of 0 to 1 .

\subsection{Relationship between Tensile Length and Initial Prestress Degree}

Fig. (3) shows the original model and the deformed model under an external load, where $L_{l}^{0}$ and $L_{2}^{0}$ are the length of SDWRB and SIWRB in the initial prestress state respectively, $\alpha_{1}^{0}$ is the angle between SDWRB and the horizontal plane in the original model, $\alpha_{2}^{0}$ is the angle between SIWRB and the horizontal plane in the original model.

In light of the geometrical relationship shown in Fig. (3), the compressed length of SDWRB, $\Delta L_{l}^{x}$, and the tensile length of SIWRB, $\Delta L_{2}^{x}$, can be expressed by the following equation:

$$
\Delta L_{1}^{x}=L_{1}^{0}-L_{1}^{x}
$$

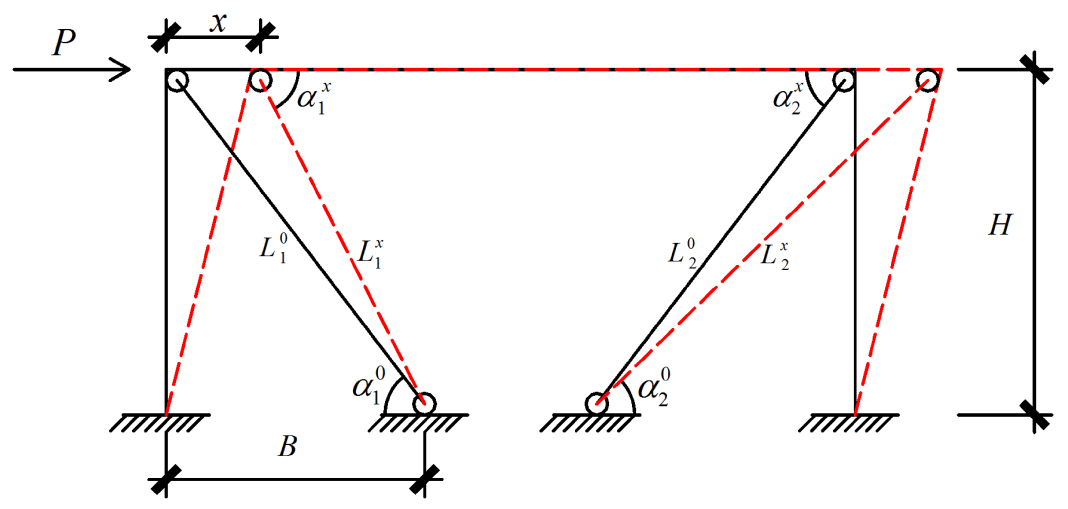

Fig. (3). Deformation comparison of PBSMF under P.

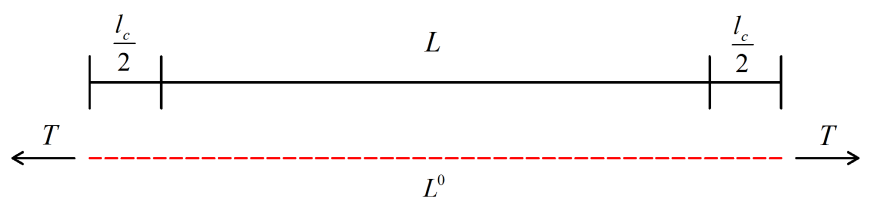

Fig. (4). Deformation of wire rope under tension T. 


$$
\Delta L_{2}^{x}=L_{2}^{x}-L_{2}^{0}
$$

The deformation of wire rope under axial external loads is portrayed in Fig. (4), where $T$ is initial tensile force of wire rope, $L$ respects the initial length of wire rope without any tension, $L^{0}$ respects the length of wire rope under $T, l_{c}$ respects the tensile length of wire rope under $T$. In terms of Hooke law and geometrical relationship shown in Fig. (4), the relationship between tensile length and initial prestress degree can be expressed as the following equation:

$$
l_{c}=\gamma f_{u} L^{0} /\left(\gamma f_{u}+E_{C}\right)
$$

\subsection{Initial Prestress Degree Formula of SDWRB}

As described in Section 3.1, the initial prestress degree criterion of SDWRB is that the tensile stress of SDWRB is more than zero under designed external loads. It also can be written as the following geometrical form:

$$
\Delta L_{1}^{x}<l_{c}
$$

By substituting Eq. (8) and Eq. (10) into Eq. (11), we obtain

$$
\gamma>\frac{E_{C}}{f_{u}}\left(\frac{\sqrt{H^{2}+B^{2}}}{\sqrt{H^{2}+(B-x)^{2}}}-1\right)
$$

Eq. (12) is the initial prestress degree formula of SDWRB, it gives the lower limit value of initial prestress degree of wire rope.

\subsection{Initial Prestress Degree Formula of SIWRB}

As described in Section 3.1, the initial prestress degree criterion of SIWRB is that the tensile stress of SIWRB is less than the designed acceptable stress under designed external loads. It also can be written as the following geometrical form:

$$
l_{c}+\Delta L_{2}^{x}<l_{d e}
$$

where, $l_{d e}$ denotes the designed acceptable tensile length of wire rope, it can be calculated by Eq. (10).

By substituting Eq. (9) and Eq. (10) into Eq. (13), we obtain

$\gamma<\frac{\sqrt{H^{2}+B^{2}}\left(E_{C}+f_{d e}\right)}{\sqrt{H^{2}+(B+x)^{2}} f_{u}}-\frac{E_{C}}{f_{u}}$

where, $f_{d e}$ is the designed acceptable stress of wire rope.

Eq. (14) is the initial prestress degree formula of SIWRB, it gives the upper limit value of initial prestress degree of wire rope.

\subsection{Initial Prestress Degree Formula of Wire Rope Brace}

The wire rope brace of PBSMF consists of SDWRB and SIWRB. It is indeterminate that the wire rope brace is SDWRB or SIWRB, due to the uncertainty of the direction of external loads. Thereby, it is necessary to consider both the initial prestress degree of SDWRB and SIWRB in determining the initial prestress degree of wire ropes of PBSMF. In light of the results of Section 3.3 and 3.4, the initial prestress degree formula of wire rope brace, which must satisfy the Eq. (12) and Eq. (14) simultaneously, can be obtained in the following form:

Eq. (15) provides the range of initial prestress degree of wire ropes, which can be used to guide the design working of the PBSMF. Eq. (15) demonstrates that the initial prestress degree is only related to story drift while the members of PBSMF are determined, and there is no correlation between initial prestress degree and sectional area of wire ropes.

$$
\left\{\begin{array}{l}
\gamma>\frac{E_{C}}{f_{u}\left(\frac{\sqrt{H^{2}+B^{2}}}{\sqrt{H^{2}+(B-x)^{2}}}-1\right)} \\
\gamma<\frac{\sqrt{H^{2}+B^{2}}\left(E_{C}+f_{d e}\right)}{\sqrt{H^{2}+(B+x)^{2}} f_{u}}-\frac{E_{C}}{f_{u}}
\end{array}\right.
$$

\section{DESIGN METHOD OF WIRE ROPE BRACE}

The determination of sectional area and initial prestress degree of wire rope brace is a pivotal problem in the design of PBSMF. Eq. (6) in Section 2 demonstrates that the lateral stiffness of PBSMF is related to sectional area of wire rope brace, thus, the story drift of PBSMF under external loads has relation with sectional area of wire rope brace. Thereby, we can design the sectional area of wire rope with respect to the relationship between the sectional area of wire rope and the story drift of PBSMF.

According to Eq. (2) and Eq. (6), we can obtain

$$
\begin{aligned}
d P= & D_{f} d x+D_{C} d x \\
D_{C} & =\left(1-\frac{\sqrt{H^{2}+(B-x-1)^{2}}}{\sqrt{H^{2}+(B-x)^{2}}}\right) E_{C} A_{C} \cos \left(\arctan \frac{H}{B-x-1}\right) \\
& +\left(\frac{\sqrt{H^{2}+(B+x+1)^{2}}}{\sqrt{H^{2}+(B+x)^{2}}}-1\right) E_{C} A_{C} \cos \left(\arctan \frac{H}{B+x+1}\right)
\end{aligned}
$$

where, $d x$ denotes the tiny story drift.

Integrating Eq. (16) gives the function of the horizontal external load with respect to story drift as follows:

where, $p$ is the total number of SDWRB, $k$ is the number of SDWRB, $A_{k C}$ is the sectional area of SDWRB $k, m$ is the total number of SIWRB, $j$ is the number of SIWRB, $A_{j C}$ is the sectional area of SIWRB $j$.

In terms of Eq. (17), it is portrayed the relations of wire rope sectional area and story drift of PBSMF in Fig. (5), while other parameters are determined. Fig. (5) indicates that story drift decreases with the growth of wire rope sectional area, and the curve is a concave shape.

Eq. (15) demonstrates that the lateral stiffness of PBSMF has no correlation with initial prestress degree of wire rope brace. It is proposed a design method of the sectional area and initial prestress degree of wire rope brace in PBSMF in light of Eq. (15) and Eq. (17). 


$$
\begin{aligned}
& P=D_{f} x+\sum_{k=1}^{p} \int_{0}^{x} \psi_{1}(x) E_{C} A_{k C} d x+\sum_{j=1}^{m} \int_{0}^{x} \psi_{2}(x) E_{C} A_{j C} d x \\
& \psi_{1}(x)=\left(1-\frac{\zeta_{1}(x)}{\zeta_{2}(x)}\right) \cos \left(\arctan \zeta_{3}(x)\right) \\
& \psi_{2}(x)=\left(\frac{\zeta_{4}(x)}{\zeta_{5}(x)}-1\right) \cos \left(\arctan \zeta_{6}(x)\right) \\
& \zeta_{1}(x)=\sqrt{H^{2}+(B-x-1)^{2}} \\
& \zeta_{2}(x)=\sqrt{H^{2}+(B-x)^{2}} \\
& \zeta_{3}(x)=\frac{H}{B-x-1} \\
& \zeta_{4}(x)=\sqrt{H^{2}+(B+x+1)^{2}} \\
& \zeta_{5}(x)=\sqrt{H^{2}+(B+x)^{2}} \\
& \zeta_{6}(x)=\frac{H}{B+x+1}
\end{aligned}
$$

The design process is divided into five steps. Firstly, it is necessary to determine the parameters, such as the designed external load, the lateral stiffness of bare steel moment frame, which can be calculated by using conventional methods, and the desired story drift. Secondly, these parameters are substituted into Eq. (17) to gain the sectional area of wire rope brace. Thirdly, the PBSMF, which has the wire rope braces with an assumed initial prestress degree and a sectional area given by second step, is analyzed. The residual tension of wire rope brace is checked, if any one of the residual tension is less than zero, the PBSMF is reanalyzed with a new assumed initial prestress degree, until all the residual tension of wire rope is greater than zero. Fourthly, the story drift of PBSMF is putted into Eq. (17) to obtain the rang of initial prestress degree, then an appropriate prestress degree, which is close to the lower limit value to obtain a higher safe capacity, is chosen to calculate the initial tensile force of wire rope brace. Finally, the final model is determined. Fig. (6) depicts the design flow chart of PBSMF.

\section{EXAMPLE}

\subsection{Wire Rope Brace Design}

This section will design the wire rope brace in a fourstory three-span PBSMF shown in Fig. (7), using the design method proposed in this paper. The details of PBSMF are the story height is $3 \mathrm{~m}$, the span is $4 \mathrm{~m}$, the beam is wide flange beam H300X200X8X12 (dimensions in mm for beam depth,

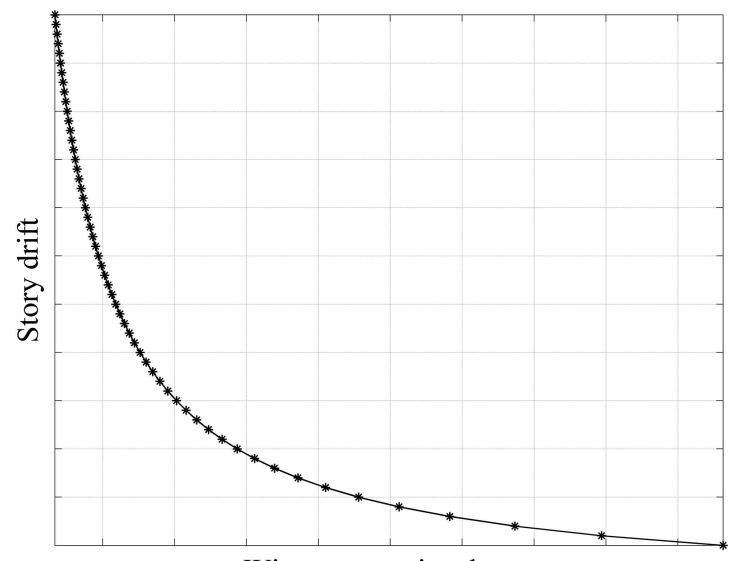

Wire rope sectional area

Fig. (5). Relation curve of wire rope sectional area and story drift.

width, web thickness and flange thickness, respectively), and the column is square steel tube $200 \times 200 \times 10$ (dimensions in $\mathrm{mm}$ for column depth, width, and thickness of column, respectively). The material of column and beam is Q235B steel. The vertical load on beam is $10 \mathrm{KN} / \mathrm{m}$. The horizontal load on joints is $120 \mathrm{KN}$ as shown in Fig. (7).

The finite element program ABAQUS is used to develop and analyze the numerical model. The finite element B21, which is a 2-node linear beam element that can transmit forces and moments in two-dimensional space, is used on beams and columns. Wire rope brace uses the finite element T2D2, which is a 2-node linear truss element that can transmit only axial force in two-dimensional space. Geometric nonlinearity is accounted for during the analysis. The load sequence is initial prestress of wire rope brace, which is produced by temperature load, vertical loads, and horizontal loads.

There are three analysis models used in this example: 4S3S-N, 4S3S-P and 4S3S-O. In the model designation, the following abbreviations are used: $4 \mathrm{~S} 3 \mathrm{~S}$ respects 4 -story 3 span steel moment-resisting frame, $\mathrm{N}$ respects the model

\begin{tabular}{|c|c|c|c|c|}
\hline Story number & 1 & 2 & 3 & 4 \\
\hline 4S3S-P prestress degree & 0.5 & 0.5 & 0.5 & 0 \\
\hline 4S3S-P tensile force $(\mathrm{KN})$ & 199.95 & 130.2 & 55.8 & 0 \\
\hline 4S3S-O tensile force $(\mathrm{KN})$ & 75.98 & 46.87 & 19.53 & 0 \\
\hline
\end{tabular}
without wire rope brace, $\mathrm{P}$ respects the model with wire rope brace whose sectional area is obtained using Eq. (17) and initial prestress is assumed, $\mathrm{O}$ respects the model with wire rope brace whose sectional area is obtained using Eq. (17) and initial prestress is optimized using Eq. (15).

The design process is shown in Fig. (6). In this example, desired story drift and initial prestress degree are set as

Table 1. Wire rope initial parameters of 4S3S-P and 4S3S-O. 
$12 \mathrm{~mm}$ and 0.5 , respectively. The brace sectional areas are listed in Table $\mathbf{1}$ which is designed using Eq. (17), it decreases from first story to forth story. There is no need to set wire rope brace in forth story due to the forth story drift in $4 \mathrm{~S} 3 \mathrm{~S}-\mathrm{N}$ is less than the desired story drift.
It is listed in Table $\mathbf{1}$ that the initial prestress degree and initial tension of $4 \mathrm{~S} 3 \mathrm{~S}-\mathrm{P}$ and $4 \mathrm{~S} 3 \mathrm{~S}-\mathrm{O}$. Table 1 shows the optimized tension is much less than the assumed tension, and $4 \mathrm{~S} 3 \mathrm{~S}-\mathrm{O}$ is safer than $4 \mathrm{~S} 3 \mathrm{~S}-\mathrm{P}$. Thereby, the analysis results indicate that the $4 \mathrm{~S} 3 \mathrm{~S}-\mathrm{O}$ is effectively optimized by using

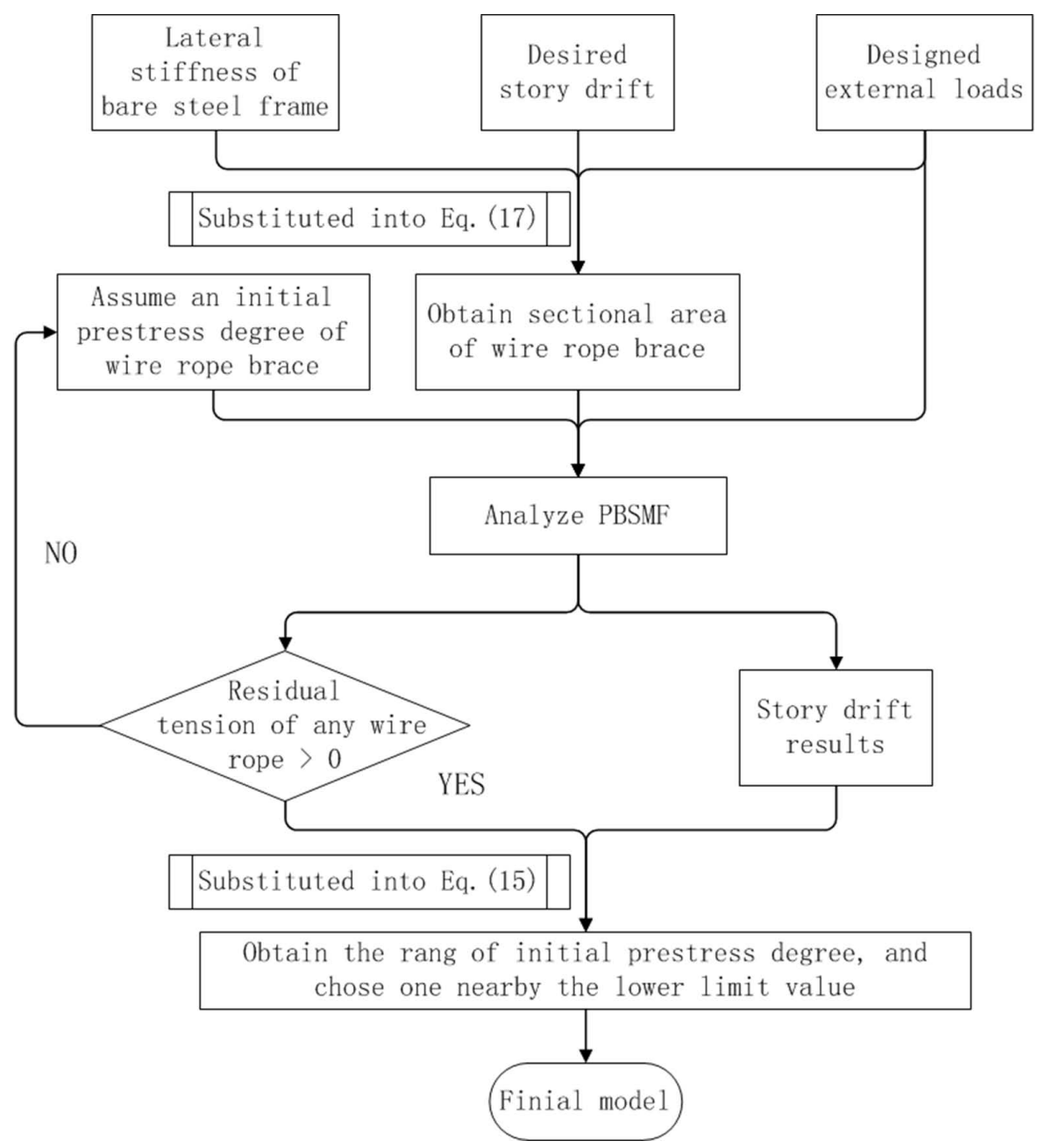

Fig. (6). Design flow chart.

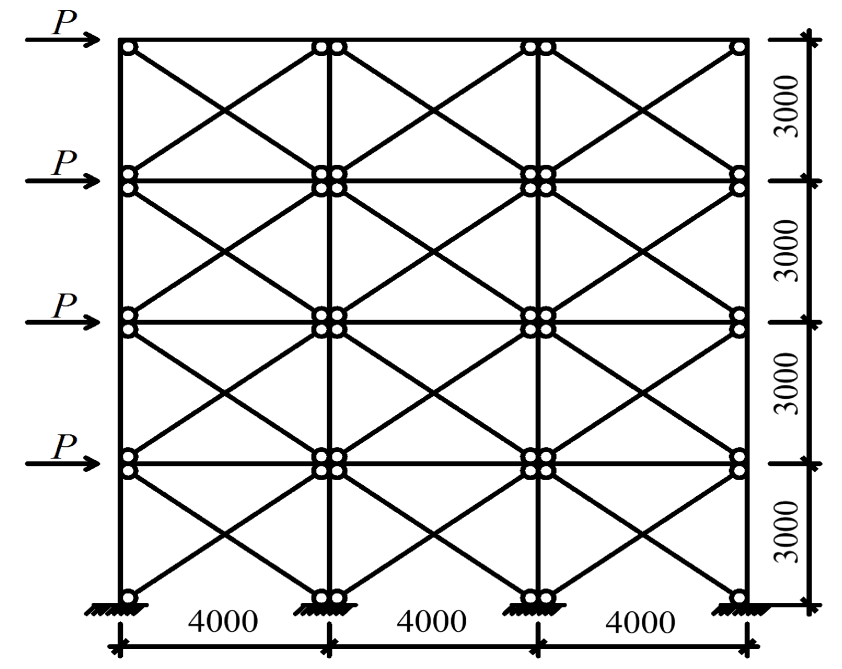

Fig. (7). A four-story three-span PBSMF model. 
Table 2. Analysis results of story drift $(\mathbf{m m})$.

\begin{tabular}{|c|c|c|c|c|}
\hline Story number & $\mathbf{1}$ & $\mathbf{2}$ & $\mathbf{3}$ & $\mathbf{4}$ \\
\hline \hline 4 S3S-N & 30.35 & 23.53 & 15.86 & 10.44 \\
\hline 4 S3S-P & 11.33 & 10.51 & 10.21 & 8.22 \\
\hline 4 S3S-O & 10.73 & 10.29 & 12 & 12 \\
\hline Desired story drift & 12 & 12 & $65.81 \%$ & $101.04 \%$ \\
\hline 4S3S-P/4S3S-N & $37.33 \%$ & $94.68 \%$ & $97.86 \%$ & $98.57 \%$ \\
\hline 4S3S-O /4S3S-P & $94.71 \%$ & $97.86 \%$ & \\
\hline
\end{tabular}

the design method proposed in this paper.

\subsection{Story Drift Comparison}

The story drifts of $4 \mathrm{~S} 3 \mathrm{~S}-\mathrm{N}, 4 \mathrm{~S} 3 \mathrm{~S}-\mathrm{P}$ and $4 \mathrm{~S} 3 \mathrm{~S}-\mathrm{O}$ are listed in Table 2 . The results reveal that wire rope brace is an effective retrofit method in reducing story drift of traditional steel frame, and the story drift of $4 \mathrm{~S} 3 \mathrm{~S}-\mathrm{O}$ reduces to $65.81 \%$ at most and $37.33 \%$ at least. The story drift comparison of the three models is depicted in Fig. (8). Fig. (8) indicates that initial tension of wire rope brace has a minimal effect, which is caused by the deformation of beams, on story drift, and the story drift of 4S3S-P and 4S3S-O meets the requirement of desired story drift. It proves the validity of proposed design methods and formulas.

\subsection{Lateral Stiffness Comparison}

Table 3 lists the lateral stiffness of 4S3S-N, 4S3S-P and $4 \mathrm{~S} 3 \mathrm{~S}-\mathrm{O}$. The results demonstrate that the wire rope brace can improve the lateral stiffness of steel moment-resisting frame effectively, and the lateral stiffness increases to $267.90 \%$ at most and $151.95 \%$ at least. Fig. (9) portrays the lateral stiffness of the three models, and illustrates that initial prestress of wire rope brace has a minimal effect, which can be ignored, on lateral stiffness. It is consistent with Eq. (6).

\subsection{Residual Tension Comparison}

The residual tensions of wire rope braces in each story are listed in Table 4, Table $\mathbf{5}$ and Table 6. The number of

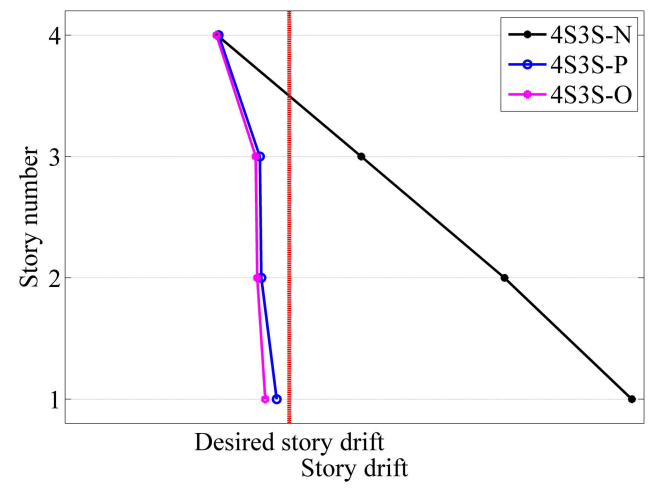

Fig. (8). Comparison curves of story drift. wire rope brace is 1 to 6 from left to right in each story. The wire rope number is denoted as $\mathrm{M}-\mathrm{N}$, where $\mathrm{M}$ is the story number, $\mathrm{N}$ is the wire rope number. The residual tensions of wire rope braces in each story are depicted in Fig. (10), Fig. (11) and Fig. (12). These figures demonstrate that no wire rope breaks due to all the residual tensions of wire ropes are less than the ultimate tension. The residual tension is reduced effectively by using the proposed optimized

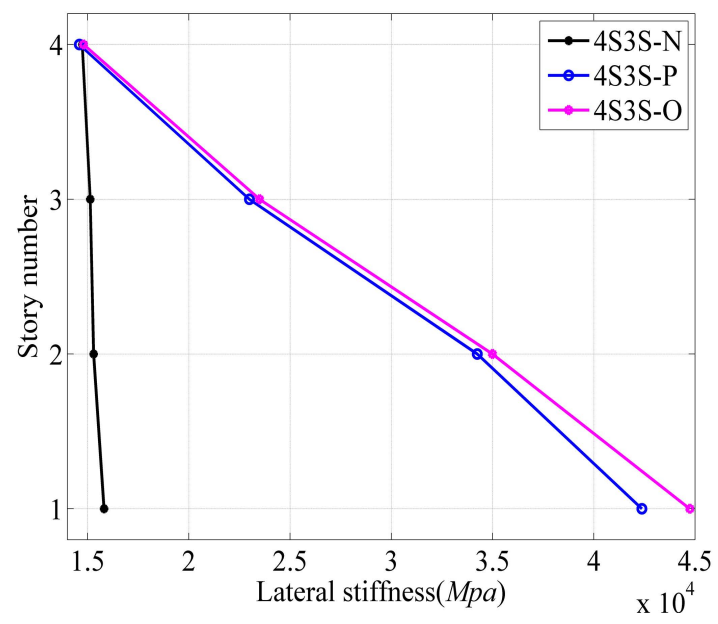

Fig. (9). Comparison curves of lateral stiffness.

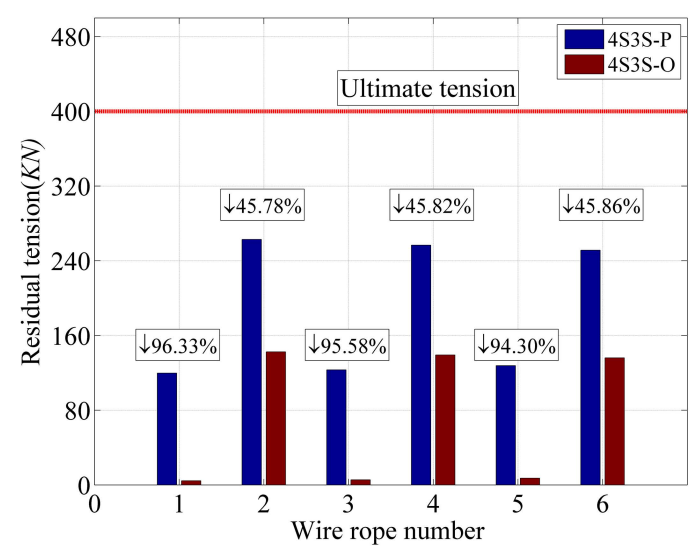

Fig. (10). Residual tension comparison of wire ropes in first floor. 


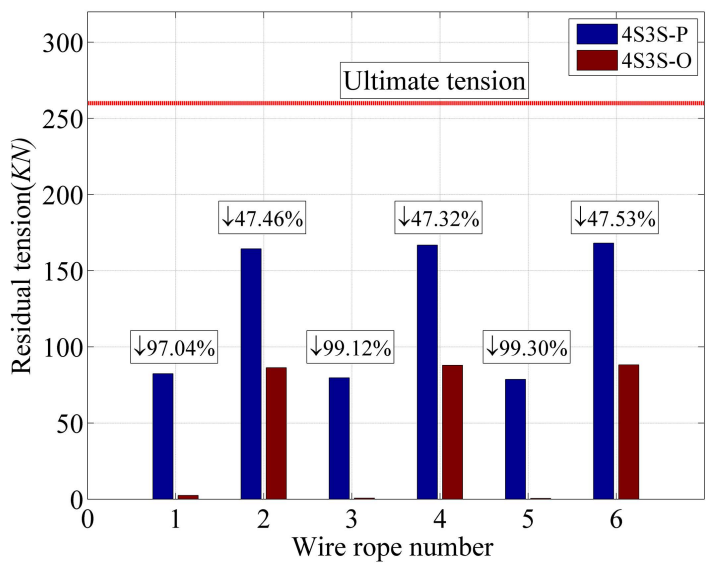

Fig. (11). Residual tension comparison of wire ropes in second floor.

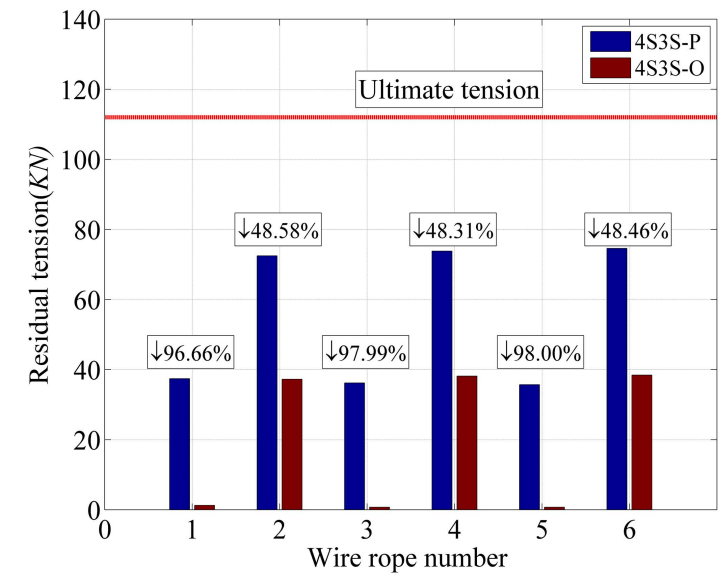

Fig. (12). Residual tension comparison of wire ropes in third floor.

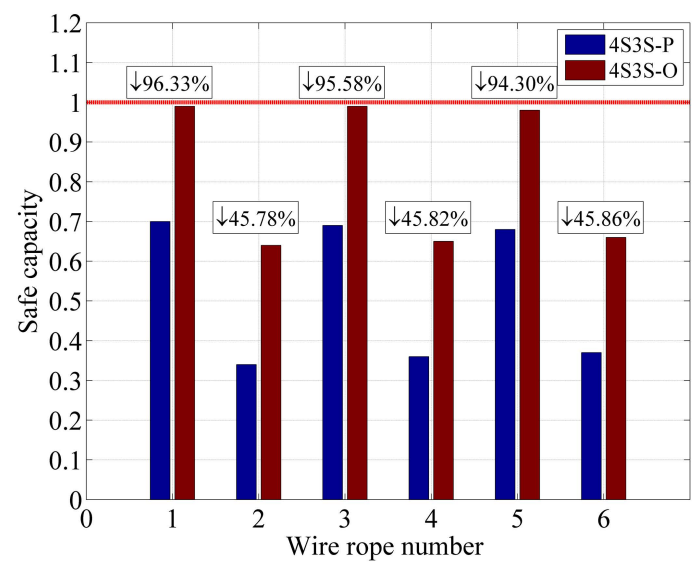

Fig. (13). Safe capacity comparison of wire ropes in first floor.

method in this paper. The residual tension of SIWRB and SDWRB reduces to $45.86 \%$ and $96.33 \%$ at most in the first story respectively, it reduces to $47.53 \%$ and $99.30 \%$ at most in second story respectively, and it reduces to $48.58 \%$ and $98.00 \%$ in third story respectively. The residual tension of
SDWRB is almost to zero, which reveals the optimized initial tension is close to the minimum initial tension which can make sure the SDWRB doesn't quit working under the designed external loads.

\subsection{Safe Capacity Comparison}

The safe capacity of wire rope brace in each story is listed in Table 7, Table $\mathbf{8}$ and Table $\mathbf{9}$ and portrayed in Fig. (13), Fig. (14) and Fig. (15). The safe capacity is increased effectively by using the design method proposed in this paper. The safe capacity of SIWRB and SDWRB increases to $45.86 \%$ and $96.33 \%$ at most in the first story respectively, it increases to $47.53 \%$ and $99.30 \%$ at most in second story respectively, and it increases to $48.58 \%$ and $98.00 \%$ in third story respectively. The safe capacity value of SDWRB is almost one, it indicates the SDWRB is almost in the safest state.

\section{CONCLUSIONS}

This study proposes a prestressed braced steel moment frame structure system (PBSMF). It is an innovation using flexible wire rope (cable) instead of rigid brace in traditional

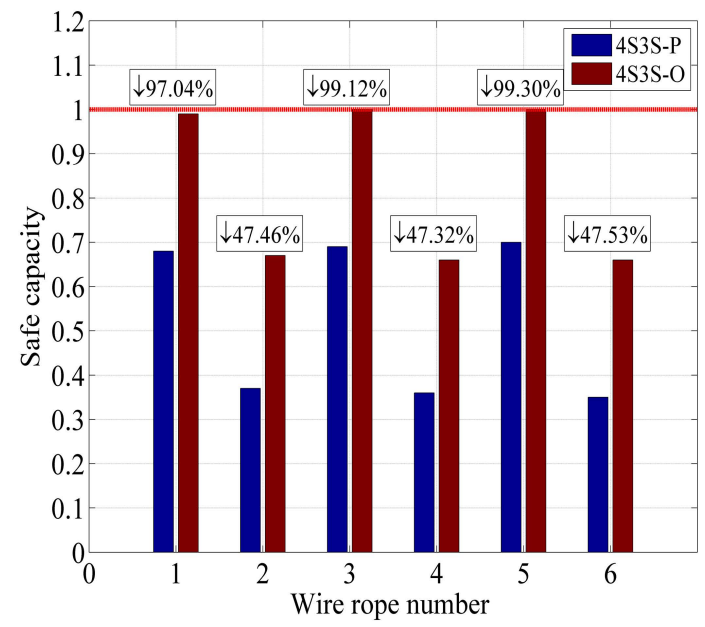

Fig. (14). Safe capacity comparison of wire ropes in second floor.

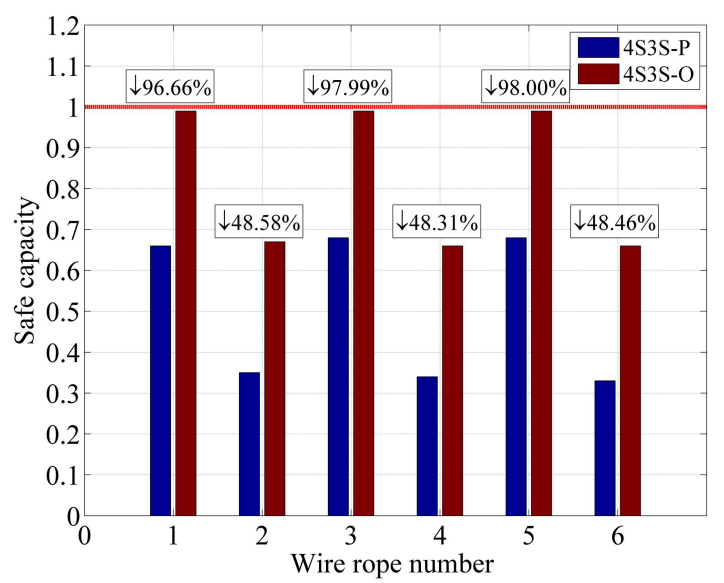

Fig. (15). Safe capacity comparison of wire ropes in third floor. 
Table 3. Analysis results of lateral stiffness (MPa).

\begin{tabular}{|c|c|c|c|c|}
\hline Story number & $\mathbf{1}$ & $\mathbf{2}$ & $\mathbf{3}$ \\
\hline \hline 4S3S-N & 15816.89 & 15301.47 & 15133.11 & 14744.64 \\
\hline 4 S3S-P & 42374.00 & 34249.82 & 22994.34 & 14593.06 \\
\hline 4 S3S-O & 44743.13 & 34999.53 & 23496.55 & 14804.27 \\
\hline 4S3S-P /4S3S-N & $267.90 \%$ & $223.83 \%$ & $151.95 \%$ & $98.97 \%$ \\
\hline 4S3S-O /4S3S-P & $105.59 \%$ & $102.19 \%$ & $102.18 \%$ & $101.45 \%$ \\
\hline
\end{tabular}

Table 4. Analysis results of cable residual tension in first floor $(\mathrm{KN})$.

\begin{tabular}{|c|c|c|c|c|c|c|}
\hline Model & Cable 1 & Cable 2 & Cable 3 & Cable 4 & Cable 5 & Cable 6 \\
\hline \hline 4S3S-P & 119.77 & 262.86 & 123.23 & 256.76 & 127.75 & 251.27 \\
\hline 4 S3S-O & 4.40 & 142.53 & 5.45 & 139.12 & 7.28 & 136.05 \\
\hline Rate of decrease & $96.33 \%$ & $45.78 \%$ & $95.58 \%$ & $45.82 \%$ & $94.30 \%$ & $45.86 \%$ \\
\hline
\end{tabular}

Table 5. Analysis results of cable residual tension in second floor (KN).

\begin{tabular}{|c|c|c|c|c|c|c|}
\hline Model & Cable 1 & Cable 2 & Cable 3 & Cable 4 & Cable 5 & Cable 6 \\
\hline \hline 4S3S-P & 82.44 & 164.37 & 79.73 & 166.82 & 78.65 & 168.12 \\
\hline 4S3S-O & 2.44 & 86.35 & 0.70 & 87.89 & 0.55 & 88.21 \\
\hline Rate of decrease & $97.04 \%$ & $47.46 \%$ & $99.12 \%$ & $47.32 \%$ & $99.30 \%$ & $47.53 \%$ \\
\hline
\end{tabular}

Table 6. Analysis results of cable residual tension in third floor (KN).

\begin{tabular}{|c|c|c|c|c|c|c|}
\hline Model & Cable 1 & Cable 2 & Cable 3 & Cable 4 & Cable 5 & Cable 6 \\
\hline \hline 4S3S-P & 37.39 & 72.45 & 36.16 & 73.81 & 35.67 & 74.57 \\
\hline 4S3S-O & 1.25 & 37.25 & 0.73 & 38.15 & 0.71 & 38.43 \\
\hline Rate of decrease & $96.66 \%$ & $48.58 \%$ & $97.99 \%$ & $48.31 \%$ & $98.00 \%$ & $48.46 \%$ \\
\hline
\end{tabular}

Table 7. Analysis results of cable safe capacity in first floor.

\begin{tabular}{|c|c|c|c|c|c|c|}
\hline Model & Cable 1 & Cable 2 & Cable 3 & Cable 4 & Cable 5 & Cable 6 \\
\hline \hline 4S3S-P & 0.70 & 0.34 & 0.69 & 0.36 & 0.68 & 0.37 \\
\hline 4S3S-O & 0.99 & 0.64 & 0.99 & 0.65 & 0.98 & 0.66 \\
\hline Rate of increase & $41.18 \%$ & $87.80 \%$ & $42.57 \%$ & $82.18 \%$ & $44.27 \%$ & $77.52 \%$ \\
\hline
\end{tabular}

Table 8. Analysis results of cable safe capacity in second floor.

\begin{tabular}{|c|c|c|c|c|c|c|}
\hline Model & Cable 1 & Cable 2 & Cable 3 & Cable 4 & Cable 5 & Cable 6 \\
\hline \hline 4S3S-P & 0.68 & 0.37 & 0.69 & 0.36 & 0.70 & 0.35 \\
\hline 4S3S-O & 0.99 & 0.67 & 1.00 & 0.66 & 1.00 & 0.66 \\
\hline Rate of increase & $44.95 \%$ & $81.24 \%$ & $43.74 \%$ & $84.35 \%$ & $42.97 \%$ & $86.61 \%$ \\
\hline
\end{tabular}

braced moment frame. Theoretical analysis is conducted to investigate the performance of PBSMF in this paper. The main conclusions are as follows:
1. The lateral stiffness formula of PBSMF is derived theoretically, and it indicates that the lateral stiffness of the PBSMF is related to the lateral stiffness of bare steel moment frame, story height, the distance between 
Table 9. Analysis results of cable safe capacity in third floor.

\begin{tabular}{|c|c|c|c|c|c|c|}
\hline Model & Cable 1 & Cable 2 & Cable 3 & Cable 4 & Cable 5 & Cable 6 \\
\hline \hline 4S3S-P & 0.66 & 0.35 & 0.68 & 0.34 & 0.68 & 0.33 \\
\hline 4S3S-O & 0.99 & 0.67 & 0.99 & 0.66 & 0.99 & 0.66 \\
\hline Rate of increase & $48.70 \%$ & $89.89 \%$ & $46.98 \%$ & $94.37 \%$ & $46.04 \%$ & $97.58 \%$ \\
\hline
\end{tabular}

column and lower end of brace, story drift, material properties and sectional properties of wire rope.

2. The lateral stiffness of PBSMF increases with the growth of story drift and the relationship curve is a concave shape.

3. The story drift of PBSMF decreases with the growth of wire rope sectional area and the relationship curve is a concave shape. In term of this, a wire rope sectional area design formula and method are proposed.

4. In light of the criterion for determining initial prestress degree, the initial prestress degree design formula and method are presented.

5. The validation of the proposed design formula and method of wipe rope brace is proved by an example analyzed by using finite element software package ABAQUS.

\section{NOTATIONS}

\begin{tabular}{|c|c|c|}
\hline$D$ & $=$ & is the lateral stiffness of PBSMF \\
\hline$D_{f}$ & $=$ & $\begin{array}{l}\text { is the lateral stiffness of bare steel moment } \\
\text { frame }\end{array}$ \\
\hline$D_{c}$ & $=$ & is the lateral stiffness of wire rope brace \\
\hline$\delta$ & $=$ & is the unit story drift \\
\hline$\delta P$ & $=$ & $\begin{array}{l}\text { is the external load with respect to unit } \\
\text { story drift }\end{array}$ \\
\hline$H$ & $=$ & is the story height \\
\hline$B$ & $=$ & $\begin{array}{l}\text { is the distance between column and lower } \\
\text { end of brace }\end{array}$ \\
\hline & $=$ & is the story drift \\
\hline$D$ & $=$ & $\begin{array}{l}\text { is the horizontal external load with respect } \\
\text { to story drift }\end{array}$ \\
\hline$L_{1}^{x}$ & $=$ & is the length of SDWRB under $P$ \\
\hline$L_{2}^{x}$ & $=$ & is the length of SIWRB under $P$ \\
\hline$\alpha_{1}^{x}$ & $=$ & $\begin{array}{l}\text { is the angle between SDWRB and the } \\
\text { horizontal plane under } P\end{array}$ \\
\hline$\alpha_{2}^{x}$ & $=$ & $\begin{array}{l}\text { is the angle between SIWRB and the } \\
\text { horizontal plane under } P\end{array}$ \\
\hline$L_{l}^{x+\delta}$ & $=$ & is the length of SDWRB under $P+\delta P$ \\
\hline$I^{x+\delta}$ & $=$ & is the length of SIWRB under $P+\delta P$ \\
\hline & $=$ & $\begin{array}{l}\text { is the angle between SDWRB and the } \\
\text { horizontal plane under } P+\delta P\end{array}$ \\
\hline
\end{tabular}

\begin{tabular}{|c|c|c|}
\hline$\alpha_{2}^{x+\delta}$ & $=$ & $\begin{array}{l}\text { is the angle between SIWRB and the } \\
\text { horizontal plane under } P+\delta P\end{array}$ \\
\hline$\Delta L_{1}^{\delta}$ & $=$ & $\begin{array}{l}\text { is the compressed length of SDWRB under } \\
\delta P\end{array}$ \\
\hline$\Delta L_{2}^{\delta}$ & $=$ & is the tensile length of SIWRB under $\delta P$ \\
\hline$\Delta T_{1}$ & $=$ & is the decreased tension of SDWRB \\
\hline$\Delta T_{2}$ & $=$ & is the increased tension of SIWRB \\
\hline$E_{C}$ & $=$ & is the elastic modulus of wire rope \\
\hline$A_{C}$ & $=$ & is the sectional area of wire rope \\
\hline$T_{d}$ & $=$ & is the designed ultimate tension \\
\hline$F_{d}$ & $=$ & is the designed external force \\
\hline$\gamma$ & $=$ & is the initial pretress degree of wire rope \\
\hline$i$ & $=$ & is the number of wire rope \\
\hline$n$ & $=$ & is the total number of wire ropes \\
\hline$T_{i}$ & $=$ & is the tensile force of wire rope $i$ \\
\hline$L_{l}^{0}$ & $=$ & $\begin{array}{l}\text { is the length of SDWRB in the initial } \\
\text { prestress state }\end{array}$ \\
\hline$L_{2}^{0}$ & $=$ & $\begin{array}{l}\text { is the length of SIWRB in the initial } \\
\text { prestress state }\end{array}$ \\
\hline$\alpha_{1}^{0}$ & $=$ & $\begin{array}{l}\text { is the angle between SDWRB and the } \\
\text { horizontal plane in the original model }\end{array}$ \\
\hline$\alpha_{2}^{0}$ & $=$ & $\begin{array}{l}\text { is the angle between SIWRB and the } \\
\text { horizontal plane in the original model }\end{array}$ \\
\hline$\Delta L_{1}^{x}$ & $=$ & $\begin{array}{l}\text { is the compressed length of SDWRB under } \\
P\end{array}$ \\
\hline$\Delta L_{2}^{x}$ & $=$ & is the tensile length of SIWRB under $P$ \\
\hline$T$ & $=$ & is the initial tensile force of wire rope \\
\hline$L$ & $=$ & $\begin{array}{l}\text { is the initial length of wire rope without } \\
\text { any tension }\end{array}$ \\
\hline$L^{0}$ & $=$ & is the length of wire rope under $T$ \\
\hline$l_{c}$ & $=$ & is the tensile length of wire rope under $T$ \\
\hline$l_{d e}$ & $=$ & $\begin{array}{l}\text { is the designed acceptable tensile length of } \\
\text { wire rope }\end{array}$ \\
\hline$f_{d e}$ & $=$ & $\begin{array}{l}\text { is the designed acceptable stress of wire } \\
\text { rope }\end{array}$ \\
\hline$d x$ & $=$ & is the tiny story drift \\
\hline$k$ & $=$ & is the number of SDWRB \\
\hline$p$ & $=$ & is the total number of SDWRB \\
\hline$j$ & $=$ & is the number of SIWRB \\
\hline
\end{tabular}




$\begin{array}{lll}m & = & \text { is the total number of SIWRB } \\ A_{k C} & = & \text { is the sectional area of SDWRB } k \\ A_{j C} & = & \text { is the sectional area of SIWRB } j .\end{array}$

\section{CONFLICT OF INTEREST}

The authors confirm that this article content has no conflict of interest.

\section{ACKNOWLEDGMENTS}

The authors deeply appreciate the generous support of the National Natural Science Foundation of China (No. 51248010) and the Beijing Natural Science Foundation (No. 8131002).

\section{REFERENCES}

[1] M. Bruneau, C. M. Uang, and A. Whittaker, Ductile Design of Steel Structures. NewYork: McGraw-Hill, 1998.

[2] M. Bruneau and T. Bhagwagar, "Seismic retrofit of flexible steel frames using infill panels", Eng. Struct., vol. 24, pp. 443-453, 2002.

[3] M. Bosco, and P.P. Rossi, "Seismic behaviour of eccentrically braced frames", Eng. Struct., vol. 31, pp. 664-674, 2009.
[4] G. Yiğitsoy, C. Topkaya, and T. Okazaki, "Stability of beams in steel eccentrically braced frames", J. Construct. Steel Res., vol. 96, pp. 14-25, 2014.

[5] E. Renzi, S. Perno, and S. Pantanella, "Design, test and analysis of a light-weight dissipative bracing system for seismic protection of structures”, Earthq Eng. Struct. Dyn., vol. 36, pp. 519-539, 2007.

[6] X. Hou, and H. Tagawa, "Displacement-restraint bracing for seismic retrofit of steel moment frames", J. Construct. Steel Res., vol. 65, pp. 1096-1104, 2009.

[7] H. Tamai, and T. Takamatsu, "Cyclic loading tests on a noncompression brace considering performance-based seismic design", J. Construct. Steel Res., vol. 61, pp. 1301-1317, 2005.

[8] R. Tremblay, "Inelastic seismic response of steel bracing members", J. Construct. Steel Res., vol. 58, pp. 665-701, 2002.

[9] Q. Xie, "State of the art of buckling-restrained braces in Asia", $J$. Construct. Steel Res., vol. 61, pp. 727-748, 2005.

[10] P. Nikos, and G. Charis, "Design and control algorithm for structures equipped with active variable stiffness devices", Struct. Control. Health Monit., vol. 17, pp. 591-613, 2010.

[11] T. Kobori, M. Takahashi, and T. Nasu, "Seismic response controlled structure with active variable stiffness system", Earthquake. Eng. Struct. Dyn., vol. 22, pp. 925-941, 1993.

[12] F. Bartera, and R. Giacchetti, "Steel dissipating braces for upgrading existing building frames", J. Construct. Steel Res., vol. 60, pp. 751-769, 2004.

[13] L. D. Sarno, and A. S. Elnashai, "Bracing systems for seismic retrofitting of steel frames", J. Construct. Steel Res., vol. 65, pp.452-465, 2009.

This is an open access article licensed under the terms of the Creative Commons Attribution Non-Commercial License (http://creativecommons.org/licenses/by-nc/3.0/) which permits unrestricted, non-commercial use, distribution and reproduction in any medium, provided the work is properly cited. 